University of Nebraska - Lincoln

DigitalCommons@University of Nebraska - Lincoln

$5-1-2006$

\title{
Self-Definition of Women Experiencing a Nontraditional Graduate Fellowship Program
}

\author{
Gayle A. Buck \\ University of Nebraska-Lincoln, gabuck@indiana.edu \\ Diandra Leslie-Pelecky \\ University of Nebraska-Lincoln, diandra2@unl.edu \\ Yun Lu \\ University of Nebraska-Lincoln \\ Vicki L. Plano Clark \\ University of Nebraska-Lincoln, vicki.planoclark@uc.edu \\ John W. Creswell \\ University of Nebraska-Lincoln, jcreswell1@unl.edu
}

Follow this and additional works at: https://digitalcommons.unl.edu/physicslesliepelecky

Part of the Physics Commons

Buck, Gayle A.; Leslie-Pelecky, Diandra; Lu, Yun; Plano Clark, Vicki L.; and Creswell, John W., "SelfDefinition of Women Experiencing a Nontraditional Graduate Fellowship Program" (2006). Diandra LesliePelecky Publications. 1.

https://digitalcommons.unl.edu/physicslesliepelecky/1

This Article is brought to you for free and open access by the Research Papers in Physics and Astronomy at DigitalCommons@University of Nebraska - Lincoln. It has been accepted for inclusion in Diandra Leslie-Pelecky Publications by an authorized administrator of DigitalCommons@University of Nebraska - Lincoln. 


\title{
Self-Definition of Women Experiencing a Nontraditional Graduate Fellowship Program
}

\author{
Gayle A. Buck, ${ }^{1}$ Diandra L. Leslie-Pelecky, ${ }^{2}$ Yun Lu, ${ }^{3}$ \\ Vicki L. Plano Clark, ${ }^{2,3}$ John W. Creswell ${ }^{3}$
}
${ }^{1}$ Department of Teaching, Learning and Teacher Education, University of Nebraska- Lincoln, 118 Henzlik Hall, Lincoln, NE 68588-0355
${ }^{2}$ Department of Physics and Astronomy, University of Nebraska-Lincoln, 156 Behlen Laboratory, Lincoln, NE 68588-0111
${ }^{3}$ Office of Qualitative and Mixed Methods Research, University of Nebraska-Lincoln, 213 Henzlik Hall, Lincoln, NE 68588-0345

Submitted November 2004; accepted 23 June 2005; published online 19 May 2006

\begin{abstract}
Women continue to be underrepresented in the fields of science, technology, engineering, and mathematics (STEM). One factor contributing to this underrepresentation is the graduate school experience. Graduate programs in STEM fields are constructed around assumptions that ignore the reality of women's lives; however, emerging opportunities may lead to experiences that are more compatible for women. One such opportunity is the Graduate Teaching Fellows in K-12 Education (GK-12) Program, which was introduced by the National Science Foundation in 1999. Although this nontraditional graduate program was not designed explicitly for women, it provided an unprecedented context in which to research how changing some of the basic assumptions upon which a graduate school operates may impact women in science. This exploratory case study examines the self-definition of 8 women graduate students who participated in a GK-12 program at a major research university. The findings from this case study contribute to higher education's understanding of the terrain women graduate students in the STEM areas must navigate as they participate in programs that are thought to be more conducive to their modes of self-definition while they continue to seek to be successful in the historically Eurocentric, masculine STEM fields.
\end{abstract}

The opinions, views, and conclusions expressed in this article may not reflect those of the funding agency. Contract grant sponsor: NSF; Contract grant number: DGE-0338202

Correspondence: Gayle A. Buck; email: gbuck@unlnotes.unl.edu

Women are still not represented in the areas of science, technology, engineering, and mathematics (STEM) at a rate equal to their representation in the U.S. population (Eisenhart, Finkel, \& Marion, 1996; National Science Board, 2004; National Science Foun- 
dation, 2004). Currently, women account for more than $50 \%$ of the U.S. population, but less than $26 \%$ of those employed in the science and engineering fields (National Science Foundation, 2004). One factor contributing to this underrepresentation of women is the graduate-school experience (Ferreira, 2003; Hirt \& Muffo, 1998). The "chilly climate" uncovered by Hall and Sandler (1982) in a study of attrition of undergraduate women in science also is experienced by women in graduate school (Dresselhaus, Franz, \& Clark, 1995; Ferreira, 2003; Hollenshead, Soellner-Younce, \& Wenzel, 1994).

The overwhelmingly male origins of the STEM fields resulted in a graduate-school experience that is based on assumptions about work, careers, family roles, and productivity that ignore the reality of women's lives (Hollenshead, Wenzel, Lazarus, \& Nair, 1996). In addition, Harding (1991) noted that women bring with them a point of view or understanding of reality that includes differences from the overarching male-dominated perspectives. These differences mean changes in a historically male-dominated community, creating additional tensions as women, and the impending transformations that will result from their increased representation, come into conflict with the current paradigm (Lave \& Wenger, 1991). Gender-role socialization, occurring prior to entering graduate school, also plays an important part in contributing to women's self-perceptions (Kahle, 1985; Sadker \& Sadker, 1994).

Women's presence and contributions need to be included in the STEM fields, as women have unique points of view and understanding of reality (Belenky, Clinchy, Goldberger, \& Tarule, 1997; Harding, 1991). The need for this diversity of approach is not just the need for the presence of the female sex but for allowing women to be women in these areas. Helping women assimilate into a male-dominated perspective does not address this need. Women must become successfully integrated, "thereby causing some change in the host institutions" (Sonnert, 1995, p. 165). The distinct differences in attrition rates between men and women in STEM disciplines in graduate school implies that we must explore how to change the host institution in a manner that is more responsive to women (Ferreira, 2003).

\section{Purpose}

The purpose of this study was to explore the self-definition of women in a graduate program funded by the National Science Foundation that was conducive to women's mode of self-definition. The phenomenon being studied, self-definition, is defined as one's identity, character, and abilities, especially in relation to persons or things outside oneself (Houghton Mifflin Company, 2000). The women were 8 graduate students in STEM fields that were given 1-year fellowships that involved experiences in Grades K-12 while pursuing their coursework/research. This nontraditional graduate fellowship program was not developed for this study nor was it developed specifically for women; however, the overrepresentation of women in this fellowship program and the subsequent identification of the characteristics which were conducive to women's mode of self-definition revealed it to be a rich context for this study. The mode of self-definition of women is defined as relationships experienced in response to others (i.e., a concern for the good of others) that is mediated through the activity of caring and grounded in interdependence (i.e., recognition of the interconnectedness of people) (Gilligan, 1977; Lyons, 1988). This nontraditional fellowship program, by virtue of its emphasis on working with teachers and K-12 students, necessitates a concern for the good of others, the activity of care, and interdependence.

Understanding the self-definition of these women in this nontraditional fellowship program will contribute to higher education's understanding of the terrain women graduate students in the STEM areas must navigate as they participate in programs that are 
thought to be conducive to their modes of self-definition while they continue to seek to be successful in the historically Eurocentric, masculine STEM fields (Harding, 1991).

\section{Case Description}

\section{The Nontraditional Fellowship Program}

The National Science Foundation's Graduate Fellows in K-12 Education Program (GK-12) was designed to make future STEM leaders aware of the issues challenging $\mathrm{K}-12$ education while they are still graduate students. The program studied in this case was 1 of 118 GK-12 programs nationally. The program was a partnership between a College of Education, College of Arts \& Sciences, and the local school district. Over a 3-year period, 24 students received 1-year fellowships to form partnerships with local teachers while pursuing graduate study in a STEM area. The fellows balanced a demanding set of tasks: classes and research plus their program responsibilities. These program responsibilities involved working 17 to $20 \mathrm{hr}$ per week toward their K-12 partnership. Extensive logistical support was provided for their activities, including weekly group meetings and the assistance of administrative staff in locating resources and coordinating logistics.

Nationwide, the representation of women in GK-12 is impressive: In 2002, 55\% of the graduate students involved in the program were female, which is significantly higher than their representation in the STEM graduate pool. In the 2003-2004 academic year, $80 \%$ of the graduate students involved in the program identified for this study were female (which was comparable to the proportion of women in the application pool). This nontraditional fellowship program had many components that value women's mode of self-definition as described by Gilligan (1977) and tested by Lyons (1988): relationships experienced as response to others (i.e., a concern for the good of others) that is mediated through the activity of caring and grounded in interdependence (i.e., recognition of the interconnectedness of people). The fellows are expected to establish yearlong relationships with $\mathrm{K}-8$ teachers, with the goal of fostering a science education for all students. The graduate students are in residence at a single school for an entire school year. In addition to co-teaching science and math at their school site, the graduate students serve as role models for the teachers and the students.

\section{The Female Graduate Students}

Eleven STEM graduate students, 8 females and 3 males, were selected to receive 1-year fellowships in this nontraditional fellowship program during the period of this study. This study focused on the group of 8 females; each is described next (Pseudonyms are used.)

Sarah was a 4th-year doctoral student, who was married and had children. At the time of application, her career goal was to work for a university; however, she was unsure if she wanted to emphasize teaching or research. Her reason to apply for this fellowship program was to "share passion for math and science with secondary students." Furthermore, from her past experience, she "has always enjoyed the interactions with children." In addition to her graduate studies, Sarah worked with one lead teacher and seven cooperating teachers in a public middle school.

Ann was a 2 nd-year doctoral student. She was married with children. At the time of application, her career goal was to work as a consultant for a large company. Her reason to apply for this fellowship program was to "share the interest and love for math and science." She also enjoyed working with children. In addition to her graduate studies, Ann worked with one lead teacher and five cooperating teachers in a public middle school. 
Mabel was a 3rd-year doctoral student. She was not married. At the time of application, her career goal was to teach at a small university. Her reason to apply for this fellowship program was to "share love and enthusiasm for math." She also wanted to "help students develop confidence to [in] math." In addition to her graduate studies, Mabel worked with one lead teacher and eight cooperating teachers in a public middle school.

Amy was a 5th-year doctoral student. She was married with children. At the time of application, her career goal was to do research as well as teach at a major university. Her reason to apply for this fellowship program was to "become a better teacher." She also stated, "I always enjoy working with children." In addition to her graduate studies, Amy worked with one lead teacher and nine cooperating teachers in a public middle school.

Katrina was a 3rd-year doctoral student. She was a single mother. At the time of application, her career goal was to work at a major research institution. Her reason to apply for this fellowship program was to "gather more teaching experience" as well as "share a passion for science." Furthermore, she wanted to "gain a better understanding of the children's world." In addition to her graduate studies, Katrina worked with one lead teacher and three cooperating teachers in a public middle school.

Kathy was a 2nd-year doctoral student. She was not married. At the time of application, her career goal was to become a science professor, with an added mission to improve conditions for women in science. Her reason to apply for this fellowship program was to "share the love for math and science with secondary students." In addition to her graduate studies, Kathy worked with one lead teacher and three cooperating teachers in a public elementary school.

Kate was a 2nd-year doctoral student. She was not married. At the time of application, her career goal was to teach at a small university. She was "excited to be a role model for children." Another reason for her to apply for the program was "to improve K-12educat ion."Furthermore, from her past experience, she "has always enjoyed helping children." In addition to her graduate studies, Kate worked with one lead teacher in a public middle school.

Mandy was a 4th-year doctoral student. She was married with children. At the time of application, her career goal was to teach and do research at a major university. Her reason to apply for this program was to "gain hands-on experience with kids." Furthermore, she "loves teaching children." In addition to her graduate studies, Mandy worked with one lead teacher and two cooperating teachers in a public middle school.

\section{Theoretical Underpinnings}

\section{Sociocultural Constructivist Theory}

Sociocultural constructivist theory advances how social and cultural interactions influence an individual's creation of understanding (Steffe \& Gale, 1995; Vygotsky, 1978; Wertsch, 1991). "A sociocultural approach to mind begins with the assumption that action is mediated and that it cannot be separated from the milieu in which it is carried out" (Wertsch, 1991, p. 18). The focus of this orientation is not on the individual learner but on learning as participation in a socially constructed world or context. Sociocultural theory of practice (Lave \& Wenger, 1991) explores both a socioculturally structured world and the persons who function within that world. Sociocultural structure refers to the institutional, historical, and social activities in which humans engage as a matter of survival and comfort (Giddens, 1979). Legitimate peripheral participation is the process by which new members become part of the community (Lave \& Wenger, 1991). The ability of a member to change the community of practice creates a tension referred to as the dialectic of practice (Giddens, 1979; Lave \& Wenger, 1991) due to the conflict as transformation is resisted by 
a tradition of social reproduction (continuity-displacement contradiction). According to Lave and Wenger (1991):

The different ways in which old-timers and newcomers establish and maintain identities conflict and generate competing viewpoints on the practice and its development. Newcomers are caught in a dilemma. On the one hand, they need to engage in the existing practice, which has developed over time: to understand it, to participate in it, and to become full members of the community in which it exists. On the other hand, they have a stake in its development as they begin to establish their own identity in the future. (p. 115)

Members of the community make decisions about their participation and act on those decisions (Giddens, 1979). Although members are guided by historical precedence, they have the ability to introduce new practices, which may change the visions of other community members.

This study focused on these women's emerging self-definitions in the context of their socially constructed world. They participated in this nontraditional fellowship program while continuing to establish their own identities in their STEM community over the course of 1 academic year. Participation in this nontraditional fellowship program changed the graduate students' experiences, emphasizing practices and understandings compatible with females' modes of self-definition but unlike the traditional graduateschool experiences in their fields. Thus, we focused on how this self-definition emerged over a 1-year period: understanding it as a period in which they participated in the nontraditional fellowship program and courses/research within their professional community of practices. Sociocultural theory of practice provided a focus for exploring how these female graduate students came to define themselves as "scientists." Did they come to define themselves as scientists? Did they view this definition of scientists to be comparable to scientists who had a traditional graduate-school experience? This theory also raised questions about how these women balanced their professional identities when emerged in an experience unlike any program experienced by the current members of their home department. If they defined themselves as a different type of scientist, did they believe they "fit" in their home departments? Did they feel pressure to change?

\section{Women's Identity Development}

Our understanding of gender differences in human development and identity formation has expanded. Gilligan (1979) noted that human development theory must accommodate for gender differences. Listening to women's discussions of moral conflicts, Gilligan (1979) recognized that women's conceptions of morality were not represented in Kohlberg's work on moral development (Gilligan, 1977, 1979). Gilligan (1979) hypothesized that there are two distinct, gender-related modes of moral judgment and that these are related to modes of self-definition. Lyons (1988) expanded on Gilligan's work by testing the hypothesis that males and females use two different modes of self-definition. Her empirical study revealed that "women more frequently use characterizations of a connected self, while men more frequently use characterizations of a separate/objective self" (Lyons, 1988, p.40). The separate/objective self defines oneself in terms of reciprocity between separate individuals (i.e., consider others as one would like to be considered) that is mediated through rules (i.e., maintain fairness and reciprocity), and grounded in roles (consider duties, obligations, and commitment). In contrast, the connected self defines oneself in terms of relationships experienced as response to others (i.e., a concern for the good of others) that is mediated through the activity of care and grounded in the recognition of the interconnectedness of people (Gilligan, 1977; Lyons, 1988). 
Identity theory is a microsociological theory that focuses on the self as a collection of identities, each of which is based on a particular role (Stryker, 1968). The roles we occupy are referred to as "role identities" (e.g., "mother" or "scientist"). Each role brings with it a set of associated meanings and expectations for the self. The various role identities that a person holds exist in a hierarchy of salience, which refers to how much importance we place on each role. The most highly ranked roles are most likely to be invoked in situations of conflict between different role identities (Stryker, 1968). Studies increasingly identify and understand how the gender differences in modes of self-definition influence men's and women's hierarchy of salience and how each gender deals with the conflict between role identities. There are similarities in how men and women rank their various roles, but also differences in their understanding of the conflict between these roles (Thoits, 1986). For example, men often believe the roles associated with their careers complement their family role as financial provider; however, women believe the roles associated with their careers conflict with their family role as caregiver and nurturer. Balancing scientific and family roles is cited by women (and some men) most frequently as a critical constraint (Scholer, 1998).

Current data do not address whether the overrepresentation of women in this nontraditional graduate program is due to the specific characteristics of this program, and there are other GK-12 programs that have predominantly male graduate students involved; however, descriptive data show that many of the features shared by this program as well as other GK-12 programs across the country are likely to be responsive to the mode of self-definition of women as described by Gilligan (1977) and tested by Lyons (1988). The program emphasizes relationships with teachers, with the goal of enhancing the lives of students. This nontraditional fellowship program necessitates a concern for the good of others, the activity of care, and interdependence. In addition, as previously described, these women held several professional roles through this program (e.g., student \& team member) and several personal roles (e.g., woman, wife, \& mother). Thus, there was a possibility of conflict.

Women's identity development provided a focus for exploring how these women experienced this nontraditional fellowship program by highlighting some views and possible conflicts that may be different from conventional understandings that may have been brought to the analysis. Specifically, it raised questions about what motivated these women to participate in this nontraditional program, whether they perceived a conflict between their professional and personal identities, and whether the components of this program that were conducive to women's modes of self-definition fostered a sense of fulfillment.

\section{Research Questions}

Four research questions were developed within the theoretical underpinnings of this study: (a) What motivated these women math and science graduate students to participate in this fellowship program? (b) Do these women feel fulfilled, and what aspects of their experience contributed to this feeling? (c) How do these women graduate students identify their role as a scientist? (d) How do these graduate students balance their professional/personal identities?

\section{Literature}

Much of this research on women in STEM fields focuses on K-12 students. A smaller, but increasing, percentage emphasizes the undergraduate level and faculty level; however, there is a very limited amount of research on female graduate students and even less about women graduate students (Ferreira, 2003; Hollenshead et al., 1996; Moyer, Salovey, 
\& Casey-Cannon, 1999). Much of the information presented here was found as subsets of larger studies focused on later stages of the career ladder (e.g., female faculty members reflecting on their graduate experiences). In referring to these studies, only those sections relevant to the graduate experience were discussed. Overall, these studies mainly focus on identifying the characteristics of the traditional graduate-school experience that impede the progress of women. Many programs were found to ultimately address those characteristics, but the literature on these programs was mainly descriptive in nature.

Project Access (Sonnert, 1995) focused on former recipients of National Science Foundation and National Research Council postdoctoral fellowships. The participants in this study had passed successfully through the earlier phases of the science "pipeline" to the point of being awarded prestigious postdoctoral fellowships. The findings related to the graduate-school experience of their participants were that (a) women tended to take a longer period of time to receive their doctoral degree, (b) women were more likely to interrupt their studies or to spend a period of time pursuing them on a part-time basis, (c) women who did interrupt their studies or spend time pursuing them on a part-time basis were less likely to leave science, $(\mathrm{d})$ women who worked more closely with their graduate advisor were more likely to leave science, and (e) women who had been research assistants were more likely to leave science. The researchers suggested that women who take time for family responsibilities tended to remain in the pipeline; however, male scientists working with these women may have had difficulty treating them as equals and instead treated them as subordinates (e.g., giving them only routine tasks to complete).

Building on research conducted in Sweden, Hodgson, Scanlon, and Whitelegg (2000) interviewed six women with Ph.D.s in different areas of physics. All of the female participants worked in higher education teaching and academic science research, scientific civil service, and science communication. Through their analysis, these researchers identified four areas of tension for women in science: isolation, departmental culture, harassment, and compromises. Isolation is associated with the lack of relationships available with others like them-women in science. This is attributed to the fact that these women are part of a minority population, and many find themselves the only female in a department. These women also often found themselves working in a culture they did not share: one of "point-scoring attitude" (p. 457). They were excluded from the men's "clubs" and, as outsiders, often found themselves the subject of both overt and covert harassment. They reported a strong sense of compromise between career and family relationships, and many reported losing considerable ground during career breaks. Similar findings were reported by Ferreira (2003) and Moyer et al. (1999).

Hollenshead et al. (1996) reviewed the research on the experiences of women graduate students in science, mathematics, and engineering. Their meta-analysis revealed that the expectations of most STEM graduate programs are constructed around assumptions about work roles, careers, family support, and productivity that ignore the reality of most women's lives. These expectations and assumptions are referred to as habits of mind. Comparing the reality of women's lives to these habits of mind reveals several discrepancies, which lead to structural obstacles that contributed to women leaving the scientific disciplines (Harding, 1991). The structural discrepancies included: (a) The amount and quality of interactions with male faculty members/advisors were lower for female students, (b) few to no female faculty members for the female students to interact with, (c) demands and routines that ignore safety considerations (i.e., walking alone to a car in the middle of the night), (d) expectations that ignore the family responsibilities that still are largely women's domain (Hochschild, 1989), and (e) an overemphasis on one way of viewing science and scientific learning that emphasizes competition and intellectual inquiry for its own sake rather than for the benefit of society. Other studies identified further obstacles, 
including (f) lack of a critical mass of females at the peer level (Dresselhaus, 1986; Kanter, 1977; National Research Council, 2001; Sonnert, 1995). For example, Dresselhaus (1986) found that the participation of women in physics classes did not occur at rates equal to the participation of males until the women comprised at least 10 to $15 \%$ of the students, (g) lack of females' involvement in issues of participation or performance of faculty (i.e., lack of responsiveness to charges of student harassment) (Fox, 2000), and (h) exclusion from collegial networking and social events (Hodgson et al., 2000).

Herzig (2004) reviewed the literature on women and students of color leaving doctoral programs in mathematics. This review revealed two significant factors associated with women and students of color remaining in the mathematics pipeline. The first significant factor is student involvement in departmental, institutional, and professional activities. Increased involvement, such as that experienced by research-assistantship holders, increased the retention and completion rate of these students (Girves \& Wemmerus, 1988; Lovitts, 2001; National Science Foundation, 1998). The second significant factor is student integration into the social structure of the profession. Using the theoretical explanations of Lave and Wenger (1991), Herzig (2004) discussed the findings of several research studies (e.g., Bass, 2003; Girves \& Wemmerus, 1998; Rogoff, 1995) to reveal the need to better integrate doctoral students into the profession of mathematics. Individual factors found to inhibit the participation and integration of women and students of color into mathematics included (a) a need for interaction, attention, and reinforcement (e.g., Etzkowitz, Kemelgor, \& Uzzi, 2000; Fennema \& Peterson, 1985); (b) a need for a structure centered on student development instead of "filtering out" (e.g., Ames, 1992); (c) a lack of confidence (e.g., Etzkowitz et al., 2000; Sonnert \& Holton, 1995); and (d) a sense of conflict with family responsibilities. Relational factors found to inhibit the participation and integration of women and students of color into mathematics included (a) a transmission model of pedagogy (e.g., Rogoff, 1994); (b) incompatible relationships with advisors (e.g., Girves \& Wemmerus, 1988; Hollenshead et al., 1994; Sonnert \& Holton, 1995); (c) patterns of isolation (e.g., Etzkowitz et al., 2000; Herzig, 2002; Hollenshead et al., 1994); and (d) a sense of competition.

These previous studies contribute to the understandings of persistence and attrition of women in traditional graduate science and mathematics programs. Common themes found in these studies include (a) women's sense of isolation, (b) lack of mentors, (c) family responsibilities, and (d) institutional climates that do not support women's success. An apparent discrepancy in the findings is the value of women spending time with their mentors or as research assistants. Sonnert (1995) found that women who spent more time with their advisors or as research assistants were more likely to leave the doctoral program; however, Hollenshead et al. (1996) and Herzig (2004) identified the limited amount of time spent with advisors or as research assistants as a barrier to women's persistence in doctoral programs. One possible explanation could be found in the stress given to "quality" time: The amount of quality time spent with advisors is a barrier to persistence while low-quality experiences may lead to more women leaving the science profession.

The challenges uncovered by these studies have been addressed in a variety of ways. A review of programs aimed at such challenges revealed a significant number of programs aimed at addressing women's sense of isolation, specifically, through increasing the number of fellowships for women in science or by bringing women from other departments/institutions together. Examples of such opportunities include fellowships specifically for women graduate students in STEM areas, found at most major universities, and by corporations such as L'Oréal, as well as networking organizations such as Graduate Women in Science and Women in Science \& Engineering at the University of Calgary. Several programs, such as MIT's Graduate Women in Physics and Duke University's Mentoring Program for Junior Women in Physical Oceanogra- 
phy, have been developed that are specifically designed to address the need for female mentors. A small, but increasing, number of programs that focus on addressing the challenges that involve institutional change can be found. Programs such as The Earth Institute at Columbia University's ADVANCE program, which is aimed at not only increasing the numbers of females in science but also through an institutional self-study (Available: http://www.earthinstitute.columbia.edu/advance/ ), and the University of Alabama at Birmingham's efforts to increase the visibility of the problems women face in academic science and engineering careers, increase the number of women in these fields, and to develop a climate in which practice and policy recognize and support the needs of women (Available: http://www.uab.edu/advance/ ). Most of these programs are new, and the literature is still descriptive in nature.

The current study expands this literature by adding a qualitative insight into women's experiences in a program that may directly address the need for institutional changes. This study goes beyond describing a program that is more compatible with females' modes of self-definition and explores the experiences of women graduate students in the program. The findings contribute to higher education's understanding of women's experiences within institutional change.

\section{Method}

To best understand the self-definition of the 8 women graduate students over the course of their 1-year participation in the nontraditional fellowship program, an exploratory case-study design guided this study (Creswell, 2002). A case study is defined as an exploration of a "bounded system" over time through detailed, in-depth data collection involving multiple sources of information (Creswell, 1998; Yin, 1994). Case studies are particularly appropriate for understanding the details and complexity of a situation (Stake, 1995). The single case examined in this study is the group of participating individuals (i.e., the 8 women STEM graduate students in the nontraditional fellowship program), bounded by time (the 2003-2004 academic year) and by place (a Midwestern U.S. university).

\section{Participants}

This study presents the responses of a group of 8 women participants, each of whom agreed to take part in this study and signed the necessary consent forms. All were U.S. citizens or permanent residents pursuing full-time study toward doctoral degrees in Mathematics (4), Statistics (1), Physical Chemistry (1), Materials Engineering (1), and Biology (1). Most anticipated a future career in teaching and/or research in higher education settings. Seven were European Americans, and 1 was Asian American. Their ages ranged from 23 to $40(M=29)$ years. Four participants were married; 3 of the married women had children, and 1 participant was a single mother.

\section{Research Team}

The research team included one female Science Education faculty member, one female faculty member in Physics, and one male faculty member specializing in Educational Research Methodology. A male doctoral student from Educational Research Methodology and a female doctoral student in Educational Research Methodology (with a master's in physics) also were part of the team. The members of this team provided for triangulation of theories by including the different theoretical constructs associated with this study (i.e., male/female and scientist/ nonscientist). 


\section{Data Collection}

Three types of qualitative data were collected in this study: focus group interviews, written documents, and individual e-mail correspondences.

Focus-Group Interviews. Focus-group interviews were the main data source for this study, as they provided an efficient means of collecting data from all participants about their experiences and perceptions during their involvement in the nontraditional fellowship program. In addition, since focus-group interviews offer the advantage of being socially oriented (Marshall \& Rossman, 1995), this format was chosen to try to increase the participants' comfort level and allow them to reflect on their own ideas as they listened to those expressed by others. Four longitudinal focus-group interviews were conducted from October 2003 to March 2004 to explore how participants' perceptions changed over the course of their participation in the program. All interviews took place at the university these participants attended and lasted 60 to $70 \mathrm{~min}$. The female educational research doctoral student conducted all four focus-group interviews.

An interview protocol was developed prior to the first interview and pilot tested with 4 women STEM graduate-student volunteers, 1 of whom had participated in the program in a previous year. Adjustments to the interview protocol based on the responses and analysis of the pilot data were made prior to the first actual interview as well as before each subsequent interview.

Based on the pilot testing, nine questions were included in the first interview protocol. The focus of the first interview was exploring the participants' ideas about their understanding of the word "scientist," the challenges of becoming a scientist, and the ways in which they perceived their career choice impacted their personal lives. Adjustments were made to the protocol used for the second interview to further probe the second and third issues. Links were made to the concepts of becoming a scientist and serving as a role model for others by adding questions such as "How do your efforts in being a role model affect your ability to be a scientist?" The questions remained the same in the third and fourth focus-group interviews; however, the probes were adjusted to allow for more exploration of the research questions. Interview questions directly related to this study included:

- In regards to your own education, what challenges do you face now, as you become a scientist?

- How do your efforts in being a role model [at the K-8 school] affect your ability to become a scientist?

- What roles do you take on at home/work/school? How do you balance them?

- In what ways do you think your career choice, including becoming a scientist and being a role model, will impact your personal life?

Written Documents. Written documents required as part of participation in the nontraditional fellowship program, such as application forms and weekly journals, were included as supplemental data sources. In the application forms, participants addressed questions about what attracted them to the fellowship program and their goals after graduation. During the academic year, all participants wrote electronic weekly journals to document their thoughts and experiences. The journals asked specific questions, such as "What have you learned as a result of this week's interactions with students? Do you think your efforts increased the participation and/or interest level of students?" Participants' responses to these weekly questions were retrieved from an electronic database and included in the overall analysis. 
E-Mail Correspondences. Specific questions related to this study were developed and sent via e-mail to clarify participant responses from the focus-group interviews and written documents. For example, one question on the application form asked participants what they hoped to do after graduation. Their responses indicated that clarification and additional information were needed, so the question "How would you describe yourself in ten years professionally and personally?" was sent electronically. Similarly, toward the end of the study, a more detailed understanding of their perceptions of the role identity of a scientist was desired. The questions "What is your definition of a scientist? Do you see yourself as what you just described? Why or why not?" were sent to the participants, and their answers were included in the data collection.

\section{Data Analysis}

All data collected in this study - focus-group transcripts, written documents, and email correspondences - were saved in text format and entered in an N6 database, a qualitative data-analysis software package (QSR N6).

Two strategic methods, direct interpretation and categorical aggregation, were used to analyze the data (Stake, 1995). This data-analysis strategy followed an inductive process of narrowing from the particular (text segments and codes) to larger themes (Creswell, 2002). After reading documents thoroughly, the researchers identified 35 codes directly from the data through an open-coding process. These codes were assigned to text segments by the researchers using the N6 software. In the second stage of analysis, the initial codes were aggregated into eight categories to identify patterns. Finally, four major themes (motivation, fulfillment, self-as-scientist, and balance) emerged from studying the patterns and collapsing the categories.

\section{Validation of the Findings}

Peer debriefings, during which the project researchers critiqued the method and checked the interpretation emerging from the data, were conducted throughout the study (Creswell \& Miller, 2000). Individual perspectives of the research team members, representing different theoretical constructs, came together to identify themes and analyze the data. Member checking also played an important role in validating the data and interpretations (Creswell \& Miller, 2000): All participants reviewed and validated the findings presented in this study.

\section{Limitations}

Case study has its limitation for advancing grand generalization (Stake, 1995). Thus, the purpose of this study is to represent this particular case, not to generalize beyond the setting. Beyond the limitation of the method design, the sample is from a self-selected group. These 8 graduate female students all applied to this nontraditional fellowship program and may have brought similar views and bias in this study. For example, most participants expressed an interest in working with children. Thus, a positive finding in self-fulfillment may be more a result of working with children (a characteristic of these particular women) specifically rather than a general concern for the good of others (part of women's modes of self-definition). In other words, the same level of self-fulfillment may not be found in experiences working with young adults or the elderly. Furthermore, because this study only included women, it lacks a more holistic view from both male and female perspectives. However, from a detailed description of this single case that this method provides, implications for other cases based on similar views and experiences can be identified. 


\section{Results}

Four major themes emerged from the data analysis: motivation, fulfillment, self-asscientist, and balance. These themes describe why the participants chose to become involved in this nontraditional fellowship program, the impact they felt from their year in a different type of graduate experience, how this experience helped shape their role as a scientist, and how they balanced conflicts in their role identities. These thematic findings are discussed in the following sections, using participant quotes as supporting evidence.

\section{Motivation: What Motivated These Participants to Choose to Participate in this Non-Traditional Fellowship Program?}

The participants discussed their reasons for choosing to participate in the fellowship program on their application forms and in the focus-group interviews. Five categories of reasons led them to choose this experience: (a) being an inspiration to students, (b) generating student interest in science at an early age, (c) enhancing their own teaching abilities, (d) wanting interactions with younger students, and (e) looking for a change from traditional graduate assistantships.

Being an Inspiration to Students. Most of the participants expressed a passion for sharing their "interest," "love," and "enthusiasm" for math and science with elementary-and middle-school students. They shared a belief that math and science are key components of education. For example, 2 participants stated that "Math and science are very important parts of education." Others shared similar views, believing that individuals could inspire students to appreciate math and science through their own views and activities. That is, by "doing the hands-on-science" and "showing how much a person can love math and science," they believed students will "learn to appreciate the beauty" and see the applications of science-related subjects. Participants wanted to be "the inspiration" for math and science so that elementary-and middle-school students would develop ability and interest in math and science.

Generating Students' Interests in Science at Early Ages. Many participants described a strong need to "generate interest in science in the early years of student lives." They mentioned the $\mathrm{K}-12$ stage as being "crucial for students to develop an understanding, appreciation, and love for math and science." Several participants were motivated by their experiences with college students and adults: "Too often I hear college students or adults discussing their difficulties with math or expressing their dislike for math," 1 participant stated. Another described that "these impressions are formed early in a person's academic career." These participants stated that they wanted to influence students' opinions and impressions toward math and science in "a favorable way." Many participants described the notion that sparking students' interest in science early in school years would make it more likely that the students would carry this interest into adulthood.

Enhancing One's Own Teaching Abilities. The participants expressed their desire to improve their teaching skills as a result of participating in this fellowship program. They wanted to be able to make science-related subjects more "understandable and more applicable." Most had prior experience as university teaching assistants assigned to introductory-level courses in their content area. They hoped that working with K-12 students would give them more ideas about "what sort of preparation" will be most useful to undergraduate students. They also anticipated that the experience of working with $\mathrm{K}-12$ school teachers would "greatly enhance" their teaching abilities because these teachers 
"work with a younger and notably harder audience." Participants wanted to gain insights from experienced teachers about "how to talk to students" as well as how to deal with students who were "unmotivated." The participants expressed the desire to have better ideas of how to carry out activities (e.g., games and group discussions) in their own teaching and expected to gain "hands-on-experience" by working with the younger children developing activities such as "designing and demonstrating experiments," tutoring students in math or science club, and "giving math or science talks" for Math Day or Science Day. Such experiences were perceived as helping them not only to "be better prepared" for their future teaching but also to "reach out" to college students who have difficulties with math or science.

Wanting Interactions with Younger Students. Each participant in this study had previous experience working with children. Participants described activities such as "teaching Sunday School kids" or "tutoring gifted high school students" or "giving science tours to kids." Participants mentioned that they enjoyed working with children, offering descriptions such as "an enjoyable experience" and "it was always so much fun to work with kids." They were motivated to join this program to continue to work and interact with children.

Looking for a Change. While the previous four categories emerged at least partly from participants' statements on their applications to the program, focus-group interviews identified an additional reason: Participants simply wanted "a change" from the more traditional graduate-teaching assistantships. One participant described that "it was nice to do something different for a year, to work with the younger kids." Another disliked her teaching-assistant duties and chose this experience expecting that "there's no way it can be worse" than serving as a teaching assistant. Another wanted to "not work with adults so much," since she thought children would be nicer and more caring than the college students. Some participants expressed a level of curiosity associated with trying this new experience. One participant explained, "I chose to do this because it was something new for me." Another said that she had not attended elementary and middle school as a youth and was "curious" as to what it was like, and viewed this as an opportunity to learn about it. Another was motivated to participate, at least partly, because she was a mother: "I wanted to see more how the kids are at that age to understand better" her own son.

\section{Fulfillment: Do These Participants Feel Fulfilled, and What Aspects of Their Experience Contribute to This Feeling?}

Participation in the fellowship program brought feelings of personal and professional fulfillment to these participants. Their experiences working with the children and the teachers made them feel that they were improving themselves as individuals and that they were valued, which brought them a sense of purpose. At the professional level, these experiences helped them gain "confidence" as scientists and renewed or enhanced their passion for doing science.

Personal Fulfillment. At the personal level, "being a role model for kids" made the participants more aware of their own behavior, and such awareness led them to feel like they were improving themselves. They perceived that their actions served as a "demonstration of how to live life to these kids," and therefore they had the responsibility to act appropriately. One participant stated that "If you know people are watching what you do ...you have to be careful what you say and do." Therefore, participants worked to practice good 
behavior (e.g., "showing respect to teachers and other students," "minding their manners," and "being polite while interacting with other people") and demonstrated good study habits (e.g., "doing homework," "being on time," and "being a good listener"). Most participants made statements consistent with "I think my life has improved because I try to do better things just because I know that they are following my example." One participant's comment provided a good example of how being a role model changed her own habits: "I usually take a snack with me, and I consciously think about eating a healthy snack and not always eating a Snickers bar. I have an apple or a piece of fruit with me." The participants also described feeling "pressure" and "stress" due to this role. As 1 participant described, "it can be stressful being on stage all the time." In balance, however, they perceived that working with the children was a positive influence on their own lives.

The participants also found personal fulfillment through their fellowship-program activities simply because they enjoyed the experiences and because they felt valued by the children and teachers. Overall, they described their time in the classrooms as "rewarding," "enjoyable," and making them "feel good." Working with kids and teachers made the participants feel that they were valued. They enjoyed having a partnership with the teachers, and felt that they were wanted and appreciated by both students and teachers. One reflected on the value of this 1-year partnership by saying: "Teaching is a really isolated job ....and it was nice, I think for me and for the teachers that I worked with, to have some kind of interaction with somebody else." The participants also appreciated feeling like they were in great demand: "If a teacher says, 'oh can you come on Friday?' ...I'll say, 'ok' and then I'll go to the school." Another example: "My lead teacher [the teacher that a graduate student works with] always asked if I could come for math club activities. And I always said yes." Some participants reported that they spent more hours in the schools than required by the program because they felt the people with whom they worked valued their presence. Most found fulfillment in the appreciation and affection shown to them by the children. They recounted stories of the children, such as: "Makes you feel good about yourself when they are smiling and happy to see you;" and "He [a student] brought his parents to the second day of conferences to meet just me ...and to say he could be a scientist just like me." One participant described that when she stopped working with a certain activity, "the kids are really upset about that, like they want me there all the time." During the focus-groups interviews, all scientists expressed that the students made them feel appreciated. A statement made by 1 participant was representative: "On the days I am not there and then I came back the next day, they [students] would always say, 'guess what we found out in science class yesterday?' It was really neat." In addition to feeling appreciated, the participants perceived that they have positively influenced many children to like science. As one stated, "I'm sure we make a difference."

Professional Fulfillment. At the professional level, these participants felt that their work with students and teachers increased their abilities to do science and reinforced their desire to be scientists. They described numerous benefits that arose from their experiences in this program. These included being more organized and learning to handle different time demands. Some participants also felt that their work had improved their overall communication skills because of having to learn to communicate at different levels with the teachers and with the children. One described that "you have to learn to relay things to people that aren't in your field of expertise; and I think that working with the middle school students really helps that." Others stated that they benefited from learning to take on new roles. For example, 1 participant described the value in having teaching experiences at different levels (as instructor, teaching assistant, and program fellow), and another noted that she had had to figure out her role in the new environment of this fellow- 
ship program. Overall, the participants described that this experience had given them more self-confidence in themselves as scientists and as professionals.

Working with the children in particular reaffirmed and enhanced the participants' passion for doing science. The scientific interest they helped encourage in the children reinforced their own interest. When describing the impact of their work in the schools on their own scientific work, participants offered comments such as: "It makes me happier about what I do" and "It always reminds me why I like my job. I tend to forget that on a day-to-day basis." Another explained that the excitement of the children reminds her of "why I like science, they always ask you 'why do you like science?' and then you have to think about it and you have to give them an answer." Working with the children also was credited with increasing scientific curiosity. One explained that "it's made me more curious, because the students are so curious and they ask me questions that I don't know the answer to, so I have to go research them."

\section{Self-as-Scientist: How Do These Participants Define Being a Scientist?}

Throughout the focus-group interviews, the participants discussed their perceptions of the role of "scientist" and how some aspects of this perception have remained the same while others have changed over time. In general, they characterized their understanding of the role of a scientist by the acts that scientists perform. These acts included working "toward discovering truths," conducting "scientific experiments," having "good logic and problem-solving skills," knowing "the process of finding out the answer and not to be afraid to try," and getting "very focused on tasks." Furthermore, a "good scientist" was described as someone who "knows the value of failure, the rewards of trying until the problem is solved and the new knowledge is discovered" and who "has passion for what they do." The participants acknowledged the existence of a canonical stereotype of a scientist, but emphasized that they had a broader definition of what it means to be a scientist. They described the role of a scientist in terms of the stereotypical view, their own expanded view, and their search to identify themselves within these views.

Scientist: The Stereotypical View. Participants discussed what they characterized as a traditional, or stereotypical, view of a scientist. They described this image of a scientist as that of Einstein, Isaac Newton, or "a little old man with glasses in a white coat, burning things, blowing things up." They related stories about famous scientists. For example, 1 participant recounted a story about Isaac Newton, stating that he "would be working on a problem, he would forget to eat or sleep and was just focused on the science he was working on" and that he did not have a family. The traditional scientist also was portrayed as one who worked alone by preference as well as due to lack of interpersonal skills. Participants expressed that they thought of traditional scientists as "loners more than working with other people" and possessing "no social life" and lacking in social skills. Participants also used terms such as "geeks" to describe the traditional scientist. One described the social skills of scientists with the following example: "Whenever they are talking to somebody, they might interrupt to make their point or things like that that they are not supposed to do in the usual setting." While these examples were almost exclusively about male scientists, the participants also briefly mentioned a few established female scientists, characterizing them as "bitter and mean and don't have families."

Scientist: An Expanded View. The participants emphasized that this stereotypical view was not how they defined a scientist, even though they had been influenced by such a view. Participants defined their view of a scientist in a much broader sense. They perceived that it is becoming acceptable to be a scientist and "still be a real person," meaning 
that a scientist may choose to have a family and a life and interests besides the science. One participant shared her observations that "all my professors have families and they have all these things they are doing on the side and I just never thought they would." Another described that "when you think of a scientist, you think of no personal life but that doesn't mean there is no personal life." One participant described the relationship between the professional and personal in the following terms: "I don't think that having less of a personal life will make you a better scientist, or the other way around." To these participants, being a scientist no longer consists solely of the stereotypical role but is now more inclusive. They explained that they thought the attitudes have been changing over the past 10 to 30 years. One participant explained that "anyone can be a scientist if they go through and get the education." Some participants did express concern about the extent to which changes were occurring. The traditional graduate program was described as expecting the "graduate student would eat, sleep and breathe his subject until he finished his Ph.D." Participants thought there were still professors not wanting graduate students with families; however, they also gave examples showing that their own experiences indicated that "the expectations of the administrators and the departments have changed a little bit, too, as these fields [math and science] have opened up more to women." As a group, these participants conveyed a new image of the scientist as having both professional dedication and success combined with a commitment to being a "real" person as well.

\section{Balance: How Do These Participants Balance Their Professional and Personal Lives?}

The fourth theme of "balance" emerged from the data analysis as intimately intertwined with the participants' perceptions of their role identity as scientists. According to the participants, "being a scientist," "having a personal life," and "being a woman with a family" do not constitute mutually exclusive roles. The participants perceived that they could "have it all" as long as they found a way to balance their professional and personal lives. The process of maintaining balance in their lives was therefore central to their development as scientists. This process included insisting on having a personal life, facing the challenges of graduate school, and striving for personal balance.

Insisting on Having a Personal Life. While the participants have replaced the traditional stereotype of scientists with a broader definition that includes having a personal life, their individual search to balance both the professional and the personal is a primary concern. As 1 participant explained, "I can't just take 4 years off from being a real person. I need to be able to do both of these things." Another added, "When I first came to graduate school, I was determined not to be like what I thought a scientist or a mathematician was. I wanted to have a life besides math." Others agreed with this sentiment through their own personal preferences. For example, 1 participant said, "I would like to have a life besides the work that I am working on." Others explained that "I just like doing things outside of school, like exercising" and "I made the rule once I had my first son that I don't work on weekends .... That does not fit a scientist image because everybody else in my lab works on weekends and I don't." Issues of having a family were particularly important to many participants. One explained, "I think that the choice to have a family at all makes us different than most scientists or at least the image of the scientist, especially as women." One participant summarized her views about being a scientist and being a wife and/or mother at this time by stating, "I think our generation of women, we now have the ability to be graduate students and scientists, but now it's our role to show that the choice doesn't have to be between family and whatever." She concluded that, "If you choose not to have a family, it's not because you were forced to choose that way." 
Facing the Challenges of Graduate School. All participants in this study were facing many challenges as they pursued their graduate degrees. The demands placed upon these women, as with most math and science graduate students, were numerous and tended to accumulate at certain times during the semesters. As 1 participant commented, "Let's just start the list." These demands included homework, tests, projects, comprehensive exams, teaching, research, writing manuscripts, and now their involvement in this nontraditional fellowship program. One participant, nearing the completion of her doctoral program, described the graduate education process as "It starts off as teaching and classes, then its teaching, classes and research, then it's teaching, classes, research, and publishing the stuff you've finished and re-writing, and re-writing, and re-writing, crying and then re-writing." She concluded by saying, "You have all of these pieces and then, if you have a family at home, it's just another piece that you're juggling." Some participants did not foresee these challenges ending with graduate school, but noted that the challenges would only continue into their future scientific careers.

While these participants did not question the need of successfully overcoming the challenges of graduate school, they did describe another aspect of the process, which 1 participant termed the "emotional challenge." This emotional challenge could be a greater hurdle than the academic challenges of pursuing a graduate degree at times. One participant explained, "I decided it wasn't so much the capability issue-can you pass the classes, jump through the hoops?" For her the challenge was more about whether the tradeoffs would be worth the end result. She wondered, "Are you willing to donate five plus years of your life to working on one project that might work?" This challenge left these participants feeling frustrated, mad, disgruntled, and lacking motivation at times. As 1 participant summarized, "frustration's the number one emotion" during graduate school.

As these participants faced the emotional and academic challenges of graduate school, they all agreed that time was an important issue. They described the need to balance the time spent on different activities (homework, teaching, family, sleep, etc.) and the difficulty of balancing these demands. As 1 participant explained, "Something's got to give if you only have 24 hours in a day." Another described the need to manage time when she said, "You really have to make sure that you're not putting too much time into any portion of your graduate career, or taking too much time away from any portion." Participants expressed that if they only had more time, they would be "getting everything done and keeping some kind of balance."

Although the fellowship duties were designed not to take more time than traditional graduate assistantships, participants' feelings of not having enough time were often intensified by the requirements of the program. They reported that their "time is very shared" among all of the demands of graduate school, the fellowship program, and their personal lives. One concern of many was not being able to work for continuous amounts of time to get things accomplished. Several said their schedule was so "back and forth" that they felt they were not "spending any real time" in the office, research lab, classes, schools, or at home. Participants also cited commuting time to and from the schools, finding parking, and walking from the car as contributing to a sense of not having enough time.

Striving for Personal Balance. Inherent in the participants' definition of what it means to be a scientist is "being able to function in both worlds." At school, they want to be good students and good scientists; on the personal side, they want to be good friends, fiancées, wives, and mothers. They described striving for personal balance, but not always having success maintaining this balance. One participant described herself as wanting to be in equilibrium, but instead finding that she was "constantly in an unstable equilibrium. You know, you tip this way, tip back this way, so it is sort of teetering on the edge of disas- 
ter." Another described herself as "completely out of balance" at one point in the year. Throughout the year, events such as a sick child, large class projects, or problems with experimental research equipment resulted in participants feeling out of balance. Participants want to spend time with their families, friends, and loved ones, but were also concerned that time spent with family resulted in other work not getting done. One described feeling that "the home part is taking a bigger role ... and I'm probably letting school slide a little bit too far." Another added, "I'd like to say that my priorities were evenly split family/home: work/school but they're not, and my balance has been home recently." Others felt guilty about neglecting their family when the demands of graduate school became dominant. Some were able to get other family members to take on new roles, such as cooking, to help keep an overall balance. One described her situation with the following: "I'm really having to think a lot about, you know, what exactly is my job and how to balance all of those demands and how to get other people to do things. I just have a lot of different hats." Another added, "I don't regret the choices I make though. I just have to accept the fact that during this four years or five years of graduate school, I just have to play less." Overall, these participants seemed to agree that if they could find the balance between their professional and personal world, they would be able to become scientists.

\section{Research Summary and Discussion}

The responses of the women in this study raise interesting questions about how the structure of this graduate-school experience, one that is conducive to women's modes of self-definition, relates to the values expressed by the participants. The women in the study express the explicit belief that being a scientist should not necessarily be exclusive of other roles. This refusal to give up values important to them for the sake of fitting the traditional view of a scientist is consistent with Lyons' (1988) findings on the modes of self-development of women. This nontraditional graduate-school experience offered the women an opportunity to participate in a project that addressed many of the issues they cited as important: They were interacting with others to the benefit of all parties, they formed caring, rewarding relationships, and they received positive feedback that they and their efforts were valued. These are consistent with the previous literature that document that the lack of attention to such issues in traditional graduate-school experiences serve as barriers to women's persistence in doctoral programs (Herzig, 2004; Hodgson et al., 2000; Sonnert, 1995) and advances this literature by providing one example of an institutional change that successfully addressed this issue.

There were some findings, however, that raise concerns about aspects of the nontraditional program. One concern is the nature of the duties associated with the program and the subsequent stress associated with balancing family roles. Although the program addresses values that women deem important and the actual time spent was not significantly greater than a traditional teaching assistantship, the nature of the duties contributed to the women feeling "out of balance" more than if they had a teaching assistantship. The program provides training and support to graduate students; however, the newness of the role may be more challenging to their balancing attempts despite it requiring no extra time. The participants traded the more familiar role of a graduate teaching assistant for the roles associated with this program, roles such as $\mathrm{K}-8$ team member, role model, and $\mathrm{K}-8$ math-and science-content expert. These findings advance the literature by providing an example on how a program that successfully addresses some of the identified characteristics of graduate school that impede the progress of women (e.g., addressing climates that do not support caring relationships) may actually exacerbate the role conflicts that have been identified as a barrier to women's persistence in doctoral 
programs (e.g., Ferreira, 2003; Herzig, 2004; Hodgson et al., 2000; Sonnert, 1995). It may be advantageous for participants to spend more than 1 year in the program, with the expectation that their familiarity with their role will decrease the balancing challenges. Despite concerns about "balancing," 5 of the 7 women eligible to participate in the program the next year applied for a second fellowship. Longitudinal studies are planned to investigate this further.

These participants have strongly expressed many of the personal/professional conflicts found in the current literature in this field as described earlier. They expressed an understanding that their decision to become a scientist is in conflict with their role as family caregiver - a finding that is conducive to Lyon's (1988) and Thoits' (1986) theories; however, they also believe that a satisfactory balance can be obtained. The participants believe that the definition of "scientist" is changing. Although they find that many professors value only the traditional definition, they felt that overall, science and society is adapting to this new definition and expressed a belief that there is a place for them in science. Part of this optimistic view may be attributed to their spending time in an environment where women were in the majority, and their feelings were validated by others. This may have allowed them to feel part of a changing population instead of as the exception to the rule.

Another concern is the lack of integration into their departments (Herzig, 2004) that may result from participation. The feelings of the women graduate students are but one component in sociocultural constructivist theory. Although some STEM funding agencies have made participation in education and outreach a requirement for research grants, many in the STEM community view education as less valuable than research. Since graduate students' careers are vested in their home departments, their participation in this program makes them part of Lave and Wenger's (1991) dialectic of practice: the process by which members can change the community of practice. In addition to being women in science, they are women in science working with $\mathrm{K}-8$ schools. This is a double conflict with the goal of social reproduction (continuity-displacement contradiction) held by many faculty. Those holding traditionally male definitions of self may not accept the value of the graduate student's participation in the program. These students may be viewed as somehow "less serious" than students following the traditional path.

During the year, the participants were engaged in a community of practice comprised of other graduate students and faculty who show support for the same values via their participation in the program. This reduced the sense of isolation that has been found to be a barrier to women's persistence in traditional doctoral programs (Dresselhaus, 1986; Herzig, 2004; Hodgson et al., 2000; Hollenshead et al., 1996; Kanter, 1977; National Research Council, 2001; Sonnert 1995). Their belief in their ability to succeed is strengthened by the observation of women around them who are successfully doing the "balancing" that is so critical, and by the assumption of the value of the enterprise; however, when they return to their home department, they lose the support of this community. Choosing to participate is a very public statement as to the importance of these values. Ultimately, there may be less conflict associated with being a female assimilated into the traditionally male structure than being a woman engaging in activities that do not fit the mold defined by the male definition of self (Sonnert, 1995). Further studies are needed to explore this conflict, and differences in the cultures of different disciplines must be explored.

Ultimately, the question of facilitating this change comes down to a personal sense of capability to balance multiple roles. The women in our study will not pursue a future in the STEM areas if it forces them to relegate other roles to unacceptably small parts of their lives. They have a need to feel that they are contributing something to others, and they are not sure that their research projects (which may or may not work) will fulfill that need. 
New ideas and modes of thinking are not only present but needed if communities of practice are to be allowed to evolve. These results illustrate the importance of addressing the values and needs that current STEM practice largely ignores; however, many prior attempts to address these gaps have been in the form of additional responsibilities and not trade-offs with other responsibilities. Our data show that time spent is not the sole consideration but that the value derived from participation appears to outweigh concerns about ability to balance roles.

In conclusion, this study revealed that these women did gravitate to a program that offered them the ability to fulfill elements in their definition of self that are lacking in the other parts of their graduate program. Additional motivations uncovered (e.g., change in routine, being respected) warrant additional inquiries to determine their importance in graduate-school experiences. It also revealed that they were able to define themselves as a woman scientist: a scientist unlike the traditional understanding of a scientist, but one that had a place in higher education; however, concerns were raised that if such programs have a large component that exists outside of the home departments, they might further prevent these women from being successfully integrated into their departments or exasperate conflicts with family roles. Thus, our findings support the value of programs that are conducive to the women's modes of self-definition, but they also raise questions about whether the issue of integration and family-role conflicts may ultimately prove to be detrimental to their persistence.

Exploring the self-definition of this group of 8 women graduate students has provided us with an increased understanding of the terrain women graduate students in the STEM fields must navigate as they participate in a program that is more conducive to their modes of self-definition while continuing to be successful in their historically Eurocentric, masculine fields. These understandings will enhance the field as it studies such programs in the pursuit of knowledge needed to transform institutions in a manner that is more responsive to women.

\section{References}

Ames, C. (1992). Classrooms: Goals, structures, and student motivation. Journal of Educational Psychology, 84, 261-271.

Bass, H. (2003). The Carnegie Initiative on the doctorate: The case of mathematics. Notices of the American Mathematical Society, 50, 767-776.

Belenky, M., Clinchy, B., Goldberger, N., \& Tarule, J. (1997). Women's ways of knowing: The development of self, voice, and mind (2nd ed.) New York: Basic Books.

Creswell, J.W. (1998). Qualitative inquiry and research design: Choosing among five traditions. Thousand Oaks, CA: Sage.

Creswell, J.W. (2002). Educational research: Planning, conducting, and evaluating quantitative and qualitative research. Upper Saddle River, NJ: Pearson Education.

Creswell, J.W., \& Miller, D. (2000). Determining validity in qualitative inquiry. Theory into Practice, 39, 124-130.

Dresselhaus, M. (1986). Women graduate students. Physics Today, 38, 74-75.

Dresselhaus, M., Franz, J., \& Clark, B. (1995). Update on the chilly climate for women in physics. The American Physical Society Committee on the Status of Women in Physics Gazette, 14, 4-9.

Eisenhart, M., Finkel, E., \& Marion, S. (1996). Creating the conditions for scientific literacy: A re-examination. American Educational Research Journal, 33, 261-295.

Etzkowitz, H., Kemelgor, C., \& Uzzi, B. (2000). Athena unbound: The advancement of women in science and technology (Vol. 19). Cambridge, England: Cambridge University Press. 
Fennema, E., \& Peterson, P. (1985). Autonomous learning behavior: A possible explanation of gender-related differences in mathematics. In L. Wilkinson \& C. Marrett (Eds.), Gender influences in classroom interaction (pp. 17-35). Madison: University of Wisconsin.

Ferreira, M. (2003). Gender issues related to graduate student attrition in two science departments. International Journal of Science Education, 25, 969-989.

Fox, M. (2000). Organizational environments and doctoral degrees awarded to women in science and engineering departments. Women's Studies Quarterly, 28, 47-61.

Giddens, A. (1979). Central problems in social theory: Action, structure and contradiction in social analysis. Berkeley: University of California Press.

Gilligan, C. (1977). Woman's place in man's life cycle. Harvard Educational Review, 49, 431-446.

Gilligan, C. (1979). Woman's place in man's life cycle. Harvard Educational Review, 49, 431-436.

Girves, J., \& Wemmerus, V. (1988). Developing models of graduate student degree progress. Journal of Higher Education, 59, 163-189.

Hall, R., \& Sandler, B. (1982). The classroom climate: A chilly one for women? Washington, DC: Project on the Status of Education of Women. Association of American Colleges.

Harding, S. (1991). Whose science? Whose knowledge? Ithaca, NY: Cornell University Press.

Herzig, A. (2002). Where have all the students gone? Participation of doctoral students in authentic mathematical activity as a necessary condition for persistence toward the Ph.D. Educational Studies in Mathematics, 50, 177-212.

Herzig, A. (2004). Becoming mathematicians: Women and students of color choosing and leaving doctoral mathematics. Review of Educational Research, 74, 171-214.

Hirt, J., \& Muffo, J. (1998). Graduate students: Institutional climates and discipline cultures. New Directions for Institutional Research, 25, 17-33.

Hochschild, A. (1989). The second shift. New York: Avon.

Hodgson, B., Scanlon, E., \& Whitelegg, E. (2000). Barriers and constraints: Women physicists' perceptions of career progress. Physics Education, 35, 454-459.

Hollenshead, C., Soellner-Younce, P., \& Wenzel, S. (1994). Women graduate students in mathematics and physics: Reflections on success. Journal of Women and Minorities in Science and Engineering, 1, 63-88.

Hollenshead, C., Wenzel, S., Lazarus, B., \& Nair, I. (1996). The graduate experience in the sciences and engineering: Rethinking gendered institutions. In C. Davis, A. Ginorio, C. Hollenshead, B. Lazarus, \& P. Raymon (Eds.), The equity equation (pp. 122-162). San Francisco: Jossey-Bass.

Houghton Mifflin Company. (2000). The American heritage dictionary of the English language (4th ed.) [Online]. Available: http://www.yourdictionary.com

Kahle, J. (Ed.). (1985). Women in science: A report from the field. New York: Falmer.

Kanter, R. (1977). Men and women of the corporation. New York: Basic Books.

Lave, J., \& Wenger, E. (1991). Situated learning: Legitimate peripheral participation. New York: Cambridge University Press.

Lincoln, Y., \& Guba, E. (1985). Naturalistic inquiry. Newbury Park, CA: Sage.

Lovitts, G. (2001). Leaving the ivory tower: A sociological analysis of the causes of departure from doctoral studies. College Park: University of Maryland.

Lyons, N. (1988). Two perspectives: On self, relationships, and morality. In C. Gilligan, J. Ward, \& J. Taylor (Eds.), Mapping the moral domain (pp. 21-48). Cambridge, MA: Harvard University Press. 
Marshall, C., \& Rossman, G.B. (1995). Designing qualitative research (2nd ed.) Thousand Oaks, CA: Sage.

Moyer, A., Salovey, P., \& Casey-Cannon. S. (1999). Challenges facing female doctoral students and recent graduates. Psychology of Women Quarterly, 23, 607-630.

National Research Council. (2001). From scarcity to visibility. Washington, DC: National Academy Press.

National Science Board. (2004). Science and engineering indicators. Arlington, VA: National Science Foundation.

National Science Foundation, Division of Science Resources Statistics, Science and Engineering Degrees, by Race/Ethnicity of Recipients: 1992-2001, NSF 04-318. Project Officers Susan T. Hill and Jean M. Johnson (Arlington, VA, 2004).

National Science Foundation, Division of Science Resource Studies. (1998). Summary of workshop on graduate student attrition (NSF Publication No. 99-314). Arlington, VA: Author.

Rogoff, B. (1994). Developing understanding of the idea of communities of learners. Mind, Culture, and Activity, 1, 209-229.

Sadker, M., \& Sadker, D. (1994). Failing at fairness: How America's schools shortchange girls. New York: Maxwell Macmillan International.

Scholer, A. (1998). Issues of gender and personal life for women in academic biology. Journal of Women and Minorities in Science and Engineering, 4, 69-89.

Sonnert, G. (1995). Gender differences in science careers. New Brunswick, NJ: Rutgers University Press.

Sonnert, G., \& Holton, G. (1995). Who succeeds in science? The gender dimension. New Brunswick, NJ: Rutgers University Press.

Stake, R. (1995). The art of case study research. Thousand Oaks, CA: Sage.

Steffe, L., \& Gale, J. (Eds.). (1995). Constructivism in education. Hillsdale, NJ: Erlbaum.

Stryker, S. (1968). Identity salience and role performance: The relevance of symbolic interaction theory for family research. Journal of Marriage and the Family, 30, 558-564.

Thoits, P. (1986). Multiple identities: Examining gender and marital status difference in distress. American Sociological Review, 51, 259-272.

Vygotsky, L. (1978). Mind in society: The development of higher psychological processes. Cambridge, MA: Harvard University Press.

Wertsch, J. (1991). Voices of the mind: A sociocultural approach to mediated action. Cambridge, MA: Harvard University Press.

Yin, R. (1994). Case study research: Design and methods (2nd ed.) Thousand Oaks, CA: Sage. 